Niğde Ömer Halisdemir Üniversitesi Mühendislik Bilimleri Dergisi
Niğde Ömer Halisdemir University Journal of Engineering Sciences

\title{
Evsel elektrik ihtiyacının hibrit yenilenebilir enerji sistemleriyle karşılanması: Bursa örneği
}

\section{Providing domestic electricity need with hybrid renewable energy systems: Bursa case study}

\author{
Sümeyye Adalı1 (iD, Melike Yalılı Kılıç2,*iD \\ ${ }^{1,2}$ Bursa Uludağ Üniversitesi, Çevre Mühendisliği Bölümü, 16059, Bursa Türkiye
}

\begin{abstract}
Özet
Gündelik yaşamın vazgeçilmez bir öğesi olan enerjiye olan talep, teknolojik gelişmeler ve dünya nüfusuna paralel olarak artış göstermektedir. Ülkeler için önemli bir gelişmişlik göstergesi sayılan enerjinin kaliteli ve sürekli olarak temin edilmesi büyük önem taşımaktadır. Fosil tabanlı enerji kaynaklarının dünya üzerinde sınırlı olması ve çevre üzerinde oluşturduğu baskı, ülkeleri alternatif enerji kaynaklarından yararlanma konusunda teşvik etmektedir. $\mathrm{Bu}$ çalışmada, evsel elektrik ihtiyacının karşılanması amacıyla HOMER Pro programı kullanılarak müstakil bir konutun 2020 yılı elektrik tüketim verileri kullanılarak şebekeye bağlı ve şebekeden bağımsız hibrit yenilenebilir enerji sistemleri tasarımı gerçekleştirilmiş̧ir. Tasarlanan enerji sistemlerinin kurulum ve işletim maliyeti hesaplanarak, sistemlerin karşılaştırılması yapılmıştır. Şebekeden bağımsız sistem için toplam net bugünkü maliyet 75749,99 TL (9159,6 \$) olarak hesaplanırken, şebekeye bağlı sistem için toplam net bugünkü maliyet 11304,57 TL (1366,9 \$) olarak hesaplanmıştır. Şebekeye bağlı sistemin konut için en uygun sistem olduğu belirlenmiştir.
\end{abstract}

Anahtar kelimeler: Yenilenebilir enerji, Elektrik, HOMER Pro, Enerji sistemi tasarımı, Konut elektriği

\section{Giriş}

Sanayi devriminden bu yana enerji elde etmek amaciyla yoğun olarak kullanılan fosil yakıtların tükenmeye başlaması ve çevre üzerinde oluşturduğu yüksek tahribat, günümüzde alternatif enerji kaynaklarının kullanımını gündeme getirmiştir [1]. Fosil yakıtlara göre çok düşük seviyede çevresel etkilere sahip olan yenilenebilir enerji kaynaklarından yararlanma, ülkelerin temiz ve tükenmez nitelikteki enerji temini hedeflerinde öne çıkmaktadır [2].

Dünyadaki fosil kaynak rezervleri incelendiğinde, petrolün 54 yıl, doğalgazın 64 yıl, kömürün ise 112 yıl yetecek düzeyde olduğu öngörülmektedir. Dünya genelinde elektrik üretiminin $\% 41$ 'i kömür, \%21'i doğalgaz, \%16's1 hidroelektrik, \%14'ü nükleer, $\% 6$ 's1 petrol ve $\% 2$ 'si ise yenilenebilir enerji santrallerinden sağlanmaktadır [3-5]. Ülkemizde 2019 yılında toplam elektrik üretiminin \%37.4'ü kömürden, \%29.4'ü hidrolik kaynaklardan, \%18.4’ü

\begin{abstract}
Demand for energy, which is an indispensable element of daily life, increases in parallel with technological developments and world population. Quality and continuous supply of energy, which is considered an important development indicator for countries, is of great importance. The limited fossil-based energy resources in the world and their pressure on the environment encourage countries to utilize alternative energy resources. In this study, grid-connected and off-grid hybrid renewable energy systems were designed using the HOMER Pro program to meet the domestic electricity need, using the electricity consumption data of 2020 for a detached house. The installation and operating costs of the designed energy systems were calculated and the systems were compared. The total net present cost for the system independent of the grid was calculated as 75749,99 TL (9159,6 \$), while the total net present cost for the system connected to the grid was calculated as 11304,57 TL (1366,9 \$). It has been determined that the system connected to the grid is the most suitable system for the house.
\end{abstract}

Keywords: Renewable energy, Electricity, HOMER Pro, Energy system design, Residential electricity

doğalgazdan, \%7.2'si rüzgar enerjisinden, $\% 3.1$ 'i güneş enerjisinden, \%3'ü jeotermal enerjiden, \%1.14'ü biyoyakıtlardan sağlanmış olup, 2018 yılından farklı olarak doğalgaz dışındaki kaynaklardan yararlanma oranında artış gerçekleşmiştir [6].

Dünyadaki başlıca yenilenebilir enerji kaynakları arasında güneş enerjisi, rüzgar enerjisi, biyokütle enerjisi, jeotermal enerji, hidrolik enerji, dalga enerjisi ve nükleer enerji yer almaktadır. Yıllık ortalama \%9.8 gibi yüksek büyüme oranına sahip olan bu kaynakların, 2040 yılına gelindiğinde enerji üretimindeki payının $\% 16.1$ olacağı öngörülmektedir [7, 8]. Enerji projeksiyonlarına göre 2050 yllında rüzgâr ve güneş enerjisinin dünya genelinde elektrik enerjisi talebinin yaklaşık \%50'sini karşılayacağ 1 belirtilmektedir [9].

Yenilenebilir enerji kaynakları içerisinde en bol, temiz ve çevre dostu olan güneş enerjisi, güneşin çekirdeğinde yer

\footnotetext{
* Sorumlu yazar / Corresponding author, e-posta / e-mail: myalili@uludag.edu.tr

Geliș / Recieved: 26.05.2021 Kabul / Accepted: 01.07.2021 Yayımlanma / Published: 27.07.2021

doi: 10.28948 /ngmuh. 943002
} 
alan füzyon süreci ile ortaya çıkmaktadır [10]. Güneş enerjisi şiddeti yaklaşı $1370 \mathrm{~W} / \mathrm{m}^{2}$ olup, bu değerin $0-1100 \mathrm{~W} / \mathrm{m}^{2}$ 'si yeryüzüne ulaşmaktadır. Güneş enerjisinin dünyaya ulaşan küçük bir bölümü bile mevcut enerji tüketiminden kat kat fazladır [11]. $\mathrm{Bu}$ nedenle güneş enerjisi, alternatif enerji kaynağı olarak önemli bir yatırım ve gelişim alanı bulmaktadır.

Ülkemizin yer aldığı coğrafi konum, güneş enerjisinden faydalanma noktasında yüksek avantajlar barındırmaktadır [12]. Türkiye Güneş Enerjisi Potansiyeli Atlasında (GEPA) ülkemizin toplam güneşlenme süresi yıllık 2741.07 saat (günlük 7.50 saat), toplam 1şınım şiddeti yıllık 1527.46 $\mathrm{kWh} / \mathrm{m}^{2}$ (günlük $4.18 \mathrm{kWh} / \mathrm{m}^{2}$ ) olarak belirtilmektedir [11]. Güneş enerjisi kullanımında önde gelen Almanya'nın güneş 1 şınım değerinin y1llık $1200 \mathrm{kWh} / \mathrm{m}^{2}$ olduğu düşünülürse, ülkemizin güneş enerjisi potansiyelinin birçok Avrupa ülkesinden yüksek değerde olduğu, fakat taşıdığı potansiyelden yeterli ölçüde yararlanılamadığı görülmektedir [13]. Ülkemizde 2020 yılında kaynakların elektrik üretimine katkısı incelendiğinde, doğalgazın 25672.9 MW'la ilk sirada yer aldığı, doğalgazı sirasıyla 22925 MW'la barajların, 10119.9 MW'la linyitin izlediği görülmektedir (Şekil 1).

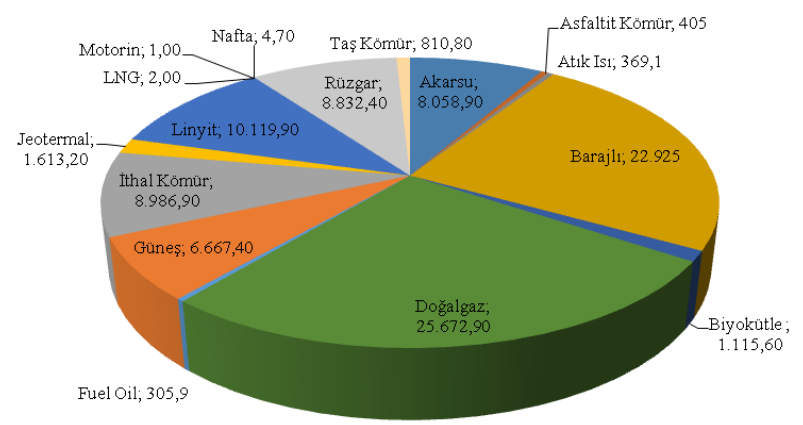

Şekil 1.Türkiye'de kaynaklara göre elektrik kurulu gücü (MW) [14]

Ülkemizde 2020 y1lı toplam elektrik kurulu gücü 95890.6 MW değerine ulaşmış olup, bu gücün 6667.4 MW'lık kısmı güneş enerjisinden sağlanmıştır. 2020 yılı sonunda ülkemizdeki güneş santrali sayısı (7481'i lisanssız olmak üzere) toplam 7518'e ulaşmıştır [14].

Bu çalışmada, Bursa ilinde yer alan müstakil bir konutun elektrik enerjisi ihtiyacının karşılanması amacıyla hibrit yenilenebilir enerji sistemi tasarlanmış ve sistemin maliyet ve uygulanabilirliği HOMER Pro programı kullanılarak belirlenmiştir.

\section{Güneş enerji sistemlerinin Dünya'da ve Türkiye'de kullanım durumu}

Güneşten elektrik eldesi amacıyla üretilen fotovoltaik sistemler dünya genelinde giderek yaygınlaşmakta ve farklı kullanım alanları bulmaktadır. Dünya yenilenebilir enerji istihdamında ilk sırada yer alan bu sistemler aracılığıyla güneş enerjisinin doğrudan elektrik enerjisine çevrimi gerçekleşebilmektedir $[10,15]$. Uluslararası enerji ajansına göre, 2050 y1lında dünya genelinde üretilen elektriğin \%11'inin fotovoltaik sistemlerle elde edileceği öngörülmektedir [2, 16].

Avrupa Birliği ülkeleri ve Türkiye'de üretilen enerjinin yaklaşık \%40'ının binalarda tüketildiği belirtilmektedir [17, 18]. Özellikle güneş enerji sistemlerinin binalarda kurulum ve kullanımı diğer yenilenebilir sistemlere kıyasla daha kolay olduğu için, güneş pilleriyle donatılmış binaların sayısında artış yaşanmaktadır [19]. Her alanda ve her büyüklükteki altyapı projelerinde kullanılabilen fotovoltaik paneller, uzun ömürlü ve çevre dostu teknolojiler olması dolayısıyla yoğun olarak tercih edilmektedir [20]. Teknolojinin gelişimiyle birlikte yüksek katlı binalarda da önemli bir kullanım alanına sahip olan güneş panelleri bu yapılarda hem enerji eldesinde bir araç olmakta hem de yapılara güneş kırıcı olarak yerleştirilerek kullanıcılar için konfor unsuru oluşturmaktadır. Bununla birlikte cephelerde dış kaplama ürünü olarak tercih edilerek yapılarda inşa aşamasında tasarruf elde edilmesine ve yapıların estetik açıdan değer kazanmasına olanak sağlamaktadır [21]. Ülkemizde ise güneş panelleri çoğunlukla sera ve binaların 1sitılmasında, park, bahçe ve otopark aydınlatmalarında, zirai ürünlerin kurutulmasında ve elektrik enerjisi üretiminde kullanılmaktadır [22].

Yenilenebilir enerji sistemlerinde, çevre ve atmosfer koşullarına bağlı olarak zaman içerisinde dalgalanmalar olmaktadır. Elektrik kesintisi gibi olası nedenlerle veya gereğinden yüksek kapasitede güneş enerjisi kurulumunu önlemek amaciyla dizel jeneratör, kurulacak enerji sistemine dâhil edilerek kurulum maliyeti düşürülebilmektedir [23,24].

Literatür incelendiğinde yenilenebilir enerji kaynaklarından elektrik eldesi ile ilgili birçok çalışmanın yer aldığ1 görülmektedir. Adıyaman ili güneş enerjisi potansiyeli ve kullanım olanaklarının araştırıldığı çalışmada, güneş enerjisi yatırımlarının il için büyük avantajlar taşıdığ belirtilmektedir [25]. Balıkesir ilinde şebekeden bağımsız ticari bir tavuk çiftliğinin elektrik ihtiyacını karşılamak amaciyla HOMER (Hybrid Optimization Model for Electric Renewable) programı kullanılarak dizel, fotovoltaik-dizelakü, rüzgâr-dizel-akü, fotovoltaik-rüzgâr-dizel akü sistem kombinasyonlarına sahip farklı hibrit sistemlerinin maliyet analizi ve çevresel performansları değerlendirilmiştir. Yapılan analizler sonucu fotovoltaik-rüzgâr-jeneratör-akü sisteminin 1088 \$ ile en avantajlı sistem olduğu belirlenmiştir [26]. Yalova'da yer alan bir çiftlik evinin elektrik ihtiyacının karşılanması amacıyla şebekeden bağımsız hibrit enerji sisteminin uygulanabilirliğinin incelendiği çalışmada, HOMER programıyla hibrit enerji sistemi için model oluşturulmuştur. Uygulanabilirlik açısından optimum şartları sağlayan $5 \mathrm{~kW}$ kapasiteye sahip PV, $4.5 \mathrm{~kW}$ kapasiteye sahip dizel jeneratör ve 18 adet $1 \mathrm{kWh}$ kapasiteye sahip akü grubu ve $3 \mathrm{kWh}$ değerine sahip konvertör ünitelerinden oluşan sistemin ilk yatırım maliyeti 30150 \$, işletme maliyeti 1309 \$, birim enerji maliyeti 0.446 $\$$ ve proje ömrü boyunca sistemin net bugünkü maliyeti 80953 \$ olarak belirlenmiştir [27]. Özbay ve Sarışık [28] tarafından yatlarda güneş enerji sistemleri kullanımı, sistemlerin verimliliği, sağladığı ekonomik ve çevresel katkılar araştırılmıştır. Yazıcı vd. [29] tarafindan HOMER Pro programı kullanılarak rüzgar, güneş ve kojenerasyon 
santrallerinden oluşan örnek bir akıllı şebeke sistemi tasarlanmış, santrallerin şebekeye elektrik üretimi ve yük paylaşımı analiz edilerek, her bir santralin ve örnek sistemin amortisman süresi hesaplanmıştır. Rüzgâr, güneş ve kojenerasyon santrallerinde toplam 4232.2 MWh elektrik enerjisi üretilmiş; üretilen enerjinin $125.39 \mathrm{kWh}$ enerjinin şebekeye satışı gerçekleşmiştir. Yatırım maliyeti 3.3 Milyon TL olan $500 \mathrm{~kW}$ 'lık güneş santralinin 4.48 yılda, 3.55 Milyon TL yatırım maliyetli $500 \mathrm{~kW}$ 'lık rüzgâr santralinin 4.38 yılda, 1.26 Milyon TL yatırım maliyeti olan $200 \mathrm{~kW}$ gücündeki gaz motorlu kojenerasyon santralinin 2.38 yılda kendisini amorti edebileceği belirlenmiş olup hibrit sistemin toplam amortisman süresi 3.91 yıl olarak hesaplanmıştır. Singh vd. [30] tarafindan Kavaratti adası için en düşük enerji maliyetine sahip hibrit rüzgâr-fotovoltaik-akü enerji sistemi HOMER Pro programı yardımıyla tasarlanmıştır. Tasarlanan sistemin 25 yıllık proje ömrü için enerji maliyeti 0.10995 $\$ / \mathrm{kWh}$, net bugünkü maliyeti $15039705 \$$ olarak belirlenmiştir.

\section{Materyal ve metot}

Bu çalışmada, Bursa ili Yıldırım ilçesine bağlı Sinandede mahallesinde bulunan $137 \mathrm{~m}^{2}$ arsa alanına ve $120 \mathrm{~m}^{2}$ 'lik kullanım alanına sahip iki katlı, iki kişinin yaşadığı müstakil bir konutun elektrik ihtiyacını karşılamak amacıyla 2020 yılı verileri baz alınarak hibrit yenilenebilir enerji sistemi tasarımı yapılmıştır. Az katlı konut varlığı nedeniyle seçilen bölgede, küçük ölçekli yenilenebilir enerji sistemlerinin konut elektrik ihtiyacının karşılanması noktasında barındırdığı avantaj ve dezavantajları belirlemek için kurulacak olan yenilenebilir enerji sistem tasarımı HOMER Pro programı kullanılarak gerçekleştirilmiştir.

Bursa ili $40^{\circ}$ boylam ve $28-30^{\circ}$ enlem daireleri arasında ülkemizin kuzeybatısında, Marmara Denizi'nin güneydoğusunda yer almaktadır. İlin nüfusu 2020 yılında 3101833'e ulaşmıştır [31]. Toplam 11 bin 027 km² 'lik alana sahip olan Bursa, 17 ilçe, 230 belde ve 659 köy yerleşimine sahiptir. Toplam alanın \%17'si ovalarla kaplıdır. Rakımı $155 \mathrm{~m}$ olan Bursa, genelde 1lıman bir iklime sahiptir. Bununla birlikte, iklim bölgelere göre de değişiklik gösterebilmektedir. Kuzeyde Marmara Denizi'nin yumuşak ve 1 lık iklimine karşılık, güneyde Uludağ'ın sert iklimi yaşanmaktadır. Şehrin en sıcak ayları temmuz ve eylül iken, en soğuk ayları ise şubat ve marttır. İlin yaklaşık \%35'i dağlarla kaplıdır [32].

Amerika'da Ulusal Yenilenebilir Enerji Laboratuvarı tarafından geliştirilen HOMER, dünyada yaygın olarak kullanılan enerji modelleme programıdır. HOMER programı fotovoltaik, rüzgâr türbinleri, akarsu hidro elektrik santrali, dizel, benzin, biyogaz, mikro türbinler, çift yakıtlı jeneratörler ve yakıt hücrelerini içeren farklı tür ve kombinasyonlardaki birçok enerji sistemi modellemesinde kolayca kullanılabilmektedir [2]. Teknoloji maliyetleri, enerji kaynaklarına ulaşılabilirlik ve geniş teknoloji seçim imkanlarını içeren teknik ve ekonomik fizibilite değerlendirmelerini içeren optimizasyon ve duyarlılık analizi sonucunda sistemlerin ekonomik uygulanabilirliği, en verimli-en ekonomik konfigürasyonu ve iyileştirmeleri, değişkenlerin ve belirsizliklerin etkisi bu yazılım kullanılarak belirlenebilmektedir [2, 33]. HOMER programındaki olası karar değişkenleri arasında fotovoltaik dizisinin boyutu, rüzgâr türbin sayısı, batarya sayısı, AC DC dönüştürücünün boyutu, Sevk stratejisi (sistemin nasıl çalıştığını belirleyen kurallar dizisi) vb. yer almaktadır. Optimizasyon sürecinde modellerle ilgili karar değişkenlerinin optimal değeri belirlenmektedir. Model kısıtlamaları, maksimum yıllık kapasite açığı ve minimum yenilenebilir fraksiyon olarak belirtilmektedir [34]. Yapılan çalışmada model duyarlılığı minimum yenilenebilir fraksiyona göre test edilmiştir.

\section{Bulgular ve tartışma}

Çalışma kapsamında örnek olarak seçilen konutun 2020 yılına ait aylık elektrik tüketim değerleri incelenmiş ve Tablo 1 'de verilmiştir.

Tablo 1.İncelenen konuta ait 2020 yllı aylık elektrik tüketim değerleri

\begin{tabular}{cccc}
\hline Aylar & $\begin{array}{c}\text { Elektrik } \\
\text { Tüketimi } \\
(\mathrm{kWh})\end{array}$ & $\begin{array}{c}\text { Ortalama Elektrik } \\
\text { Tüketimi } \\
(\mathrm{kWh} / \text { gün })\end{array}$ & $\begin{array}{c}\text { Tutar } \\
(\mathrm{TL})\end{array}$ \\
\hline Ocak & 103.571 & 3.237 & 73 \\
Şubat & 110.806 & 3.574 & 79 \\
Mart & 94.995 & 3.276 & 68 \\
Nisan & 93.849 & 3.352 & 66 \\
Mayıs & 104.245 & 3.475 & 74 \\
Haziran & 149.722 & 4.830 & 107 \\
Temmuz & 146.791 & 4.735 & 104 \\
Ağustos & 183.300 & 5.391 & 130 \\
Eylül & 153.243 & 5.284 & 109 \\
Ekim & 138.523 & 4.777 & 100 \\
Kasım & 128.796 & 4.025 & 97 \\
Aralık & 106.750 & 3.558 & 80 \\
\hline & Toplam $=$ & Yaklaş1k y1llık & Toplam $=$ \\
& 1514.591 & ortalama $=4.13$ & 1087 \\
\hline
\end{tabular}

Tablo 1 incelendiğinde elektrik tüketiminin 183.300 $\mathrm{kWh}$ ile ağustos ayında en yüksek değerde, $93.849 \mathrm{kWh}$ ile nisan ayında en düşük değerde gerçekleştiği belirlenmiştir.

Şekil 2'de Bursa ili yıllık güneş radyasyon haritası yer almaktadır.

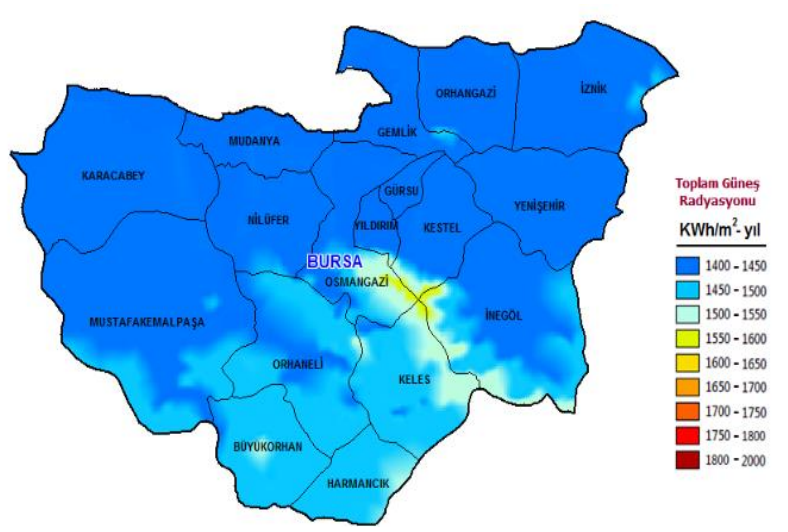

Şekil 2.Bursa İli yıllık güneş radyasyon haritası [35]

Çalışmanın yürütüldüğü bölgeye ait ortalama günlük radyasyon değerleri ve hava açıklık indeksleri (Tablo 2) HOMER programı kullanılarak NASA Yüzey meteorolojisi ve Güneş Enerjisi veri tabanından elde edilmiştir. 
Tablo 2. Çalışmanın yürütüldüğü bölgeye ait açıklık indeksi ortalama günlük radyasyon ve rüzgâr hızı değerleri

\begin{tabular}{cccc}
\hline Aylar & $\begin{array}{c}\text { Açıklık } \\
\text { indeksi }\end{array}$ & $\begin{array}{c}\text { Günlük radyasyon } \\
\left(\mathrm{kWh} / \mathrm{m}^{2} / \mathrm{Gün}\right)\end{array}$ & $\begin{array}{c}\text { Ortalama Rüzgar } \\
\text { Hızı }(\mathrm{m} / \mathrm{s})\end{array}$ \\
\hline Ocak & 0.397 & 1.670 & 5.840 \\
Şubat & 0.412 & 2.310 & 6.270 \\
Mart & 0.459 & 3.490 & 5.420 \\
Nisan & 0.464 & 4.460 & 4.800 \\
Mayıs & 0.536 & 5.910 & 4.280 \\
Haziran & 0.579 & 6.710 & 4.270 \\
Temmuz & 0.602 & 6.790 & 5.070 \\
Ağustos & 0.587 & 5.930 & 5.200 \\
Eylül & 0.567 & 4.690 & 4.910 \\
Ekim & 0.484 & 2.990 & 5.560 \\
Kasım & 0.417 & 1.880 & 5.500 \\
Aralık & 0.367 & 1.390 & 5.740 \\
\hline
\end{tabular}

Çalışma kapsamında incelenen konut için, hibrit enerji sistemleri şebekeden bağımsız ve şebekeye bağlı olarak iki ayrı şekilde incelenmiştir. Şebekeye bağlı sistemde yenilenebilir enerji eldesi için fotovoltaik panellerden yararlanılmış olup, şebekeden bağımsız sistemde fotovoltaik panellerin yanı sıra enerji depolama amaciyla batarya ve elektrik ihtiyacının karşılanamadığı durumlar için dizel jeneratör kurulumu gerçekleştirilmiştir. Şekil 3 'te incelenen konut için oluşturulan sistem tasarımları yer almaktadır. Şebekeden bağımsız sistem için en uygun yenilenebilir fraksiyon oranı yapılan duyarlılık analizi neticesinde \%40 olarak belirlenmiştir. Dizel yakıt fiyatı $6.47 \mathrm{TL} / \mathrm{L}$ olarak alınmıştır [36]. Şebekeden bağımsız sistemde en yüksek emisyon değeri, $44.5 \mathrm{~kg} \mathrm{CO} / \mathrm{CO}_{2} 1$ olarak belirlenmiştir. Şebekeden bağımsız enerji sisteminin maliyeti 75749.99 TL (9159.6 \$) olarak hesaplanmıştır [37].Şebekeden bağımsız sistem için yenilenebilir fraksiyon, jeneratör minimum yük

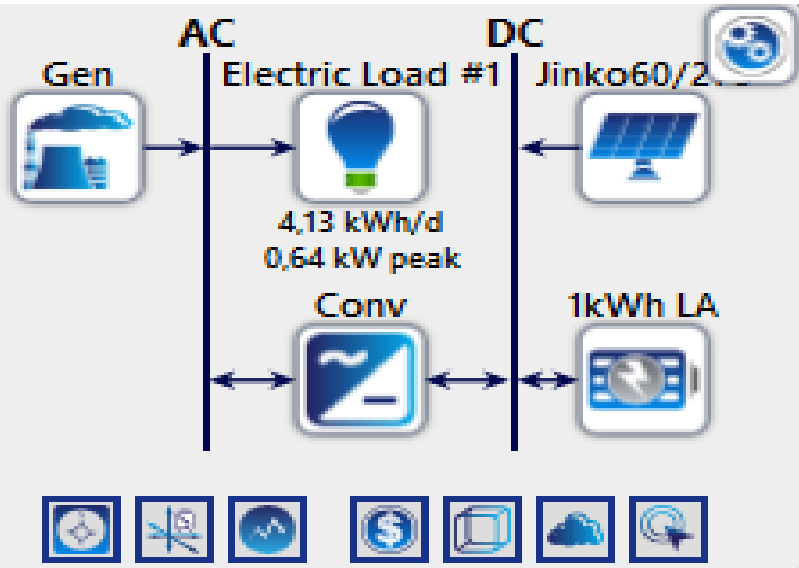

(a) oranı için belirlenen değerlere göre en uygun sisteme ait analiz sonuçları Tablo 3-6'da yer almaktadır.

Tablo 3. Şebekeden bağımsız sisteme ait maliyet özeti

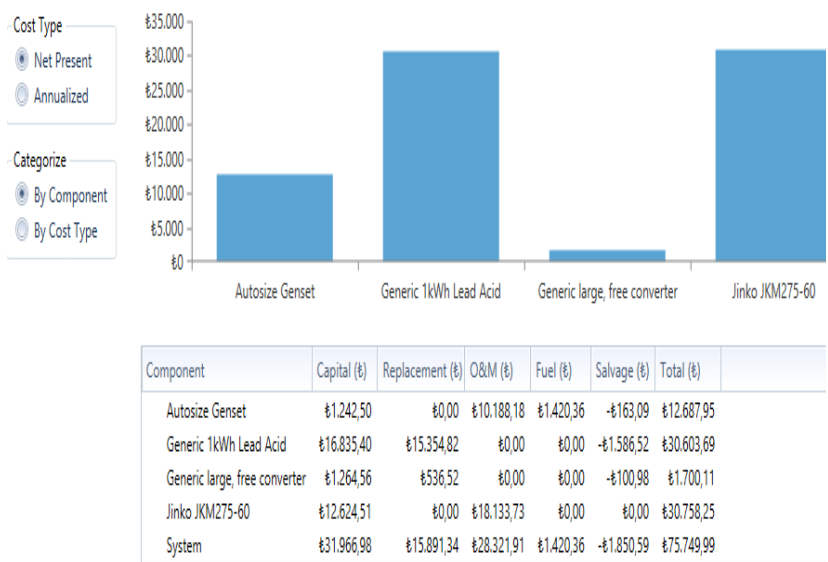

Tablo 4. Şebekeden bağımsız sistem PV güç çıkışı

\begin{tabular}{|l|l|l|}
\hline Quantity & Value & Units \\
\hline Rated Capacity & 3,86 & $\mathrm{~kW}$ \\
\hline Mean Output & 0,612 & $\mathrm{~kW}$ \\
Mean Output & 14,7 & $\mathrm{kWh} / \mathrm{d}$ \\
Capacity Factor & 15,9 & $\%$ \\
Total Production & 5,358 & $\mathrm{kWh} / \mathrm{yr}$ \\
\hline
\end{tabular}

\begin{tabular}{|l|l|l|}
\hline Quantity & Value & Units \\
\hline Minimum Output & 0 & $\mathrm{~kW}$ \\
Maximum Output & 4,05 & $\mathrm{~kW}$ \\
PV Penetration & 355 & $\%$ \\
Hours of Operation & 4,393 & $\mathrm{hrs} / \mathrm{yl}$ \\
Levelized Cost & 0,444 & $\mathrm{t} / \mathrm{kW}$ \\
\hline
\end{tabular}
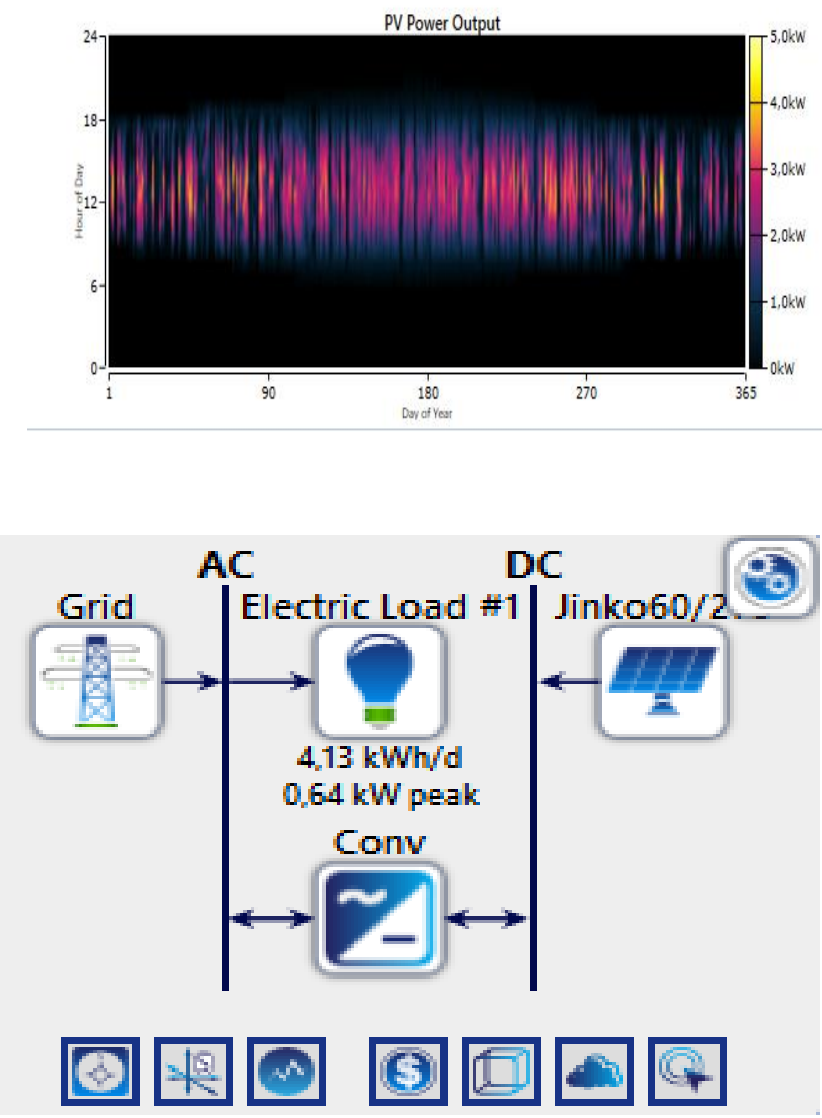

(b)

Şekil. 3.İncelenen konut için oluşturulan sistem tasarımları (a) şebekeden bağımsız sistem ve (b) şebekeye bağlı sistem 
Tablo 5. Şebekeden bağımsız sistem jeneratör güç çıkışı

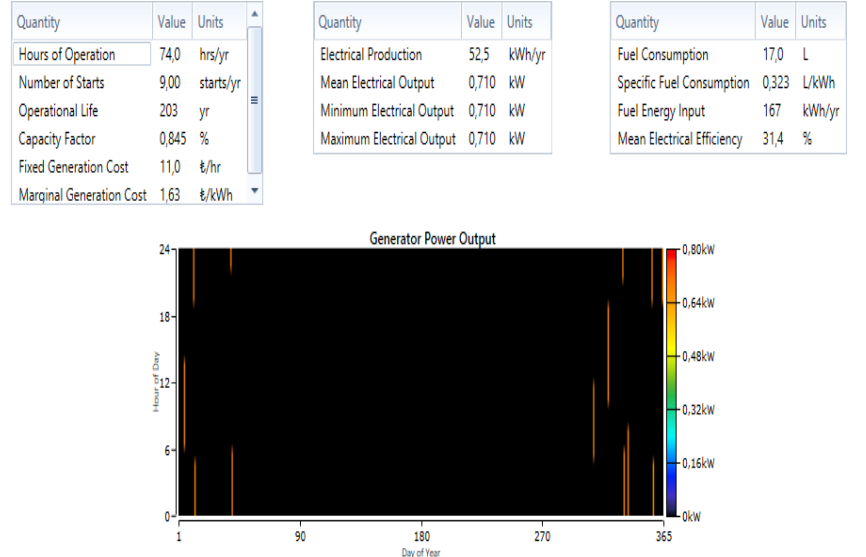

Tablo 6. Şebekeden bağımsız sistemde elektrik üretimi
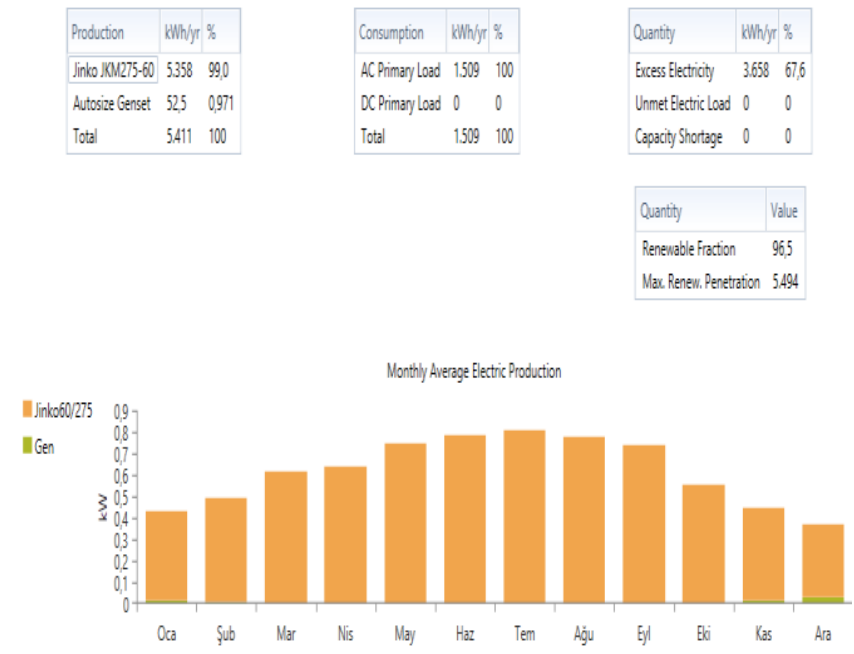

Şebekeye bağlı sisteme ait simülasyon sonuçları Tablo 7 10 'da yer almaktadır.

Tablo 7. Şebekeye bağlı sisteme ait maliyet özeti

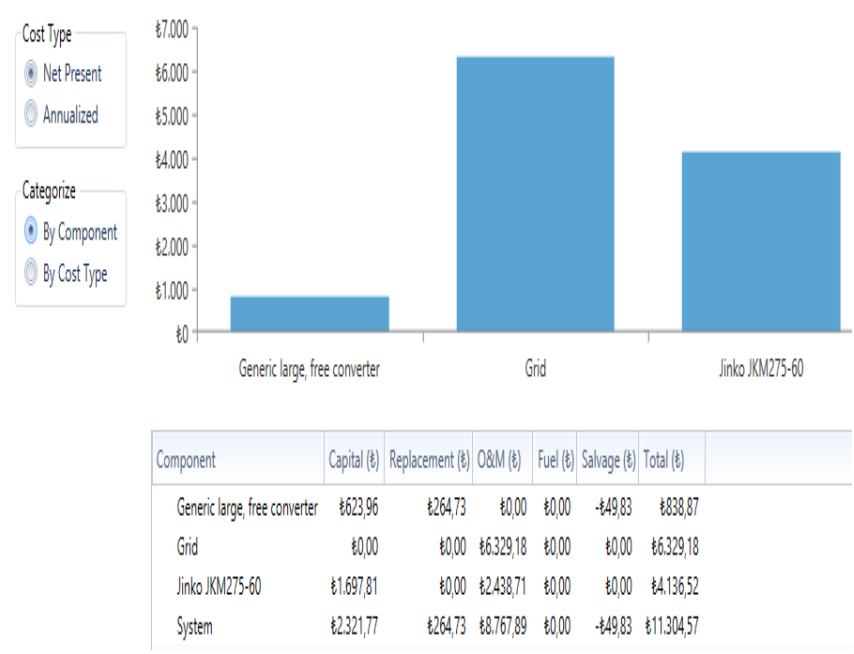

Tablo 8. Şebekeye bağlı sistem PV güç çıkışı

\begin{tabular}{|l|l|l|l|l|l|l|}
\hline Quantity & Value & Units & & Quantity & Value & Units \\
\hline Rated Capacity & 0,519 & $\mathrm{~kW}$ & & Minimum Output & 0 & $\mathrm{~kW}$ \\
\hline Mean Output & 0,0823 & $\mathrm{~kW}$ & & Maximum Output & 0,545 & $\mathrm{~kW}$ \\
Mean Output & 1,97 & $\mathrm{kWh} / \mathrm{d}$ & & PV Penetration & 47,8 & $\%$ \\
Capacity Factor & 15,9 & $\%$ & & Hours of Operation & 4,393 & $\mathrm{hrs} / \mathrm{yr}$ \\
\hline Total Production & 721 & $\mathrm{kWh} / \mathrm{yr}$ & & Levelized Cost & 0,444 & $\mathrm{t} / \mathrm{kWh}$ \\
\hline
\end{tabular}

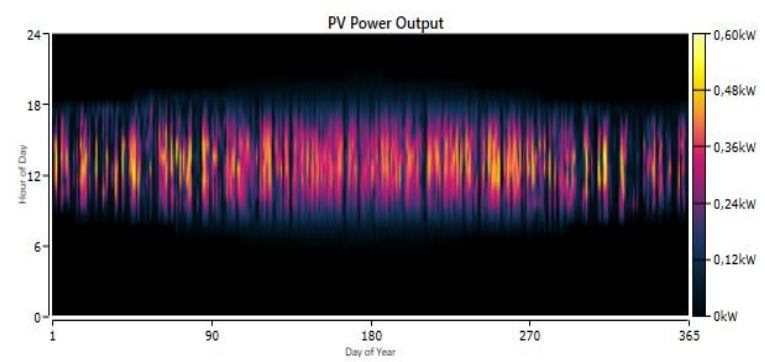

Tablo 9. Şebekeye bağlı sistemde elektrik üretimi
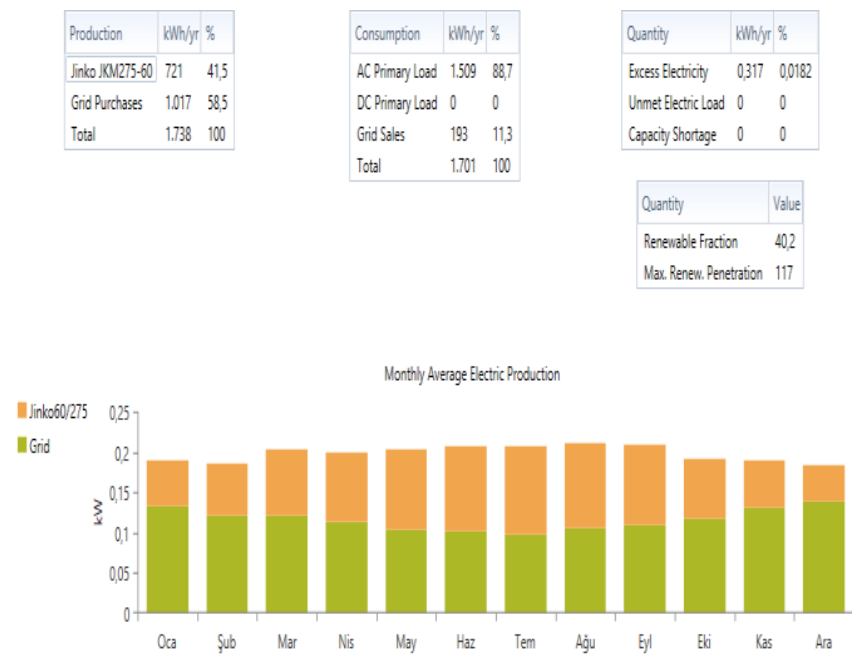

Tablo 10. Şebekeden alınan ve üretilen enerji değerleri

\begin{tabular}{|c|c|c|c|c|c|c|}
\hline Month & $\begin{array}{l}\text { Energy } \\
\text { Purchsed } \\
\text { (WWh) }\end{array}$ & $\begin{array}{l}\text { Energy } \\
\text { Sold [WWh] }\end{array}$ & $\begin{array}{l}\text { Net Enetgy } \\
\text { Purchsed } \\
\text { (WWh) }\end{array}$ & $\begin{array}{l}\text { Peak } \\
\text { Demand } \\
\text { (KW) }\end{array}$ & $\begin{array}{l}\text { Energy } \\
\text { Chargege (t) }\end{array}$ & $\begin{array}{l}\text { Demand } \\
\text { Charge }(\xi)\end{array}$ \\
\hline May & 76 & 21 & 55 & 1 & $\$ 3465$ & t0 \\
\hline June & 73 & 21 & 53 & 1 & $\$ 33,22$ & $\$ 0$ \\
\hline July & 73 & 23 & 50 & 1 & $\$ 32,16$ & t0 \\
\hline August & 79 & 21 & 58 & 0 & $\{36,26$ & to \\
\hline September & 79 & 22 & 58 & 1 & $\$ 36,07$ & \$0 \\
\hline October & 87 & 14 & 73 & 1 & $\{4279$ & $\$ 0$ \\
\hline November & 95 & 11 & 84 & 1 & $\{47,67$ & to \\
\hline December & 103 & 7 & 96 & 1 & $\$ 5532,23$ & 30 \\
\hline Anvual & 1017 & 193 & 825 & 1 & $\$ 499,59$ & : 0 \\
\hline
\end{tabular}

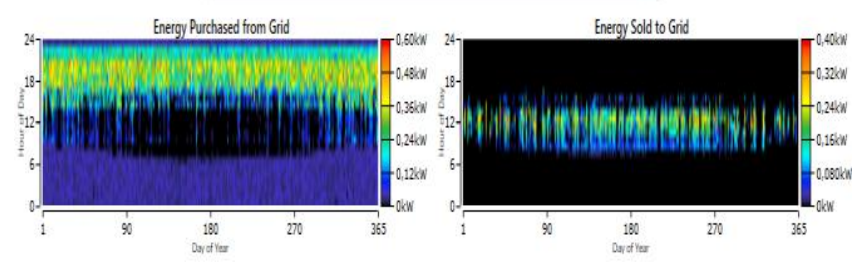

Şebekeye bağlı sistem için şebekeden çekilen elektrik maliyeti $0.54 \mathrm{TL} / \mathrm{kW}$; şebekeye satılan elektrik maliyeti $0.31 \mathrm{TL} / \mathrm{kW}$ olarak programa girilmiştir [38]. Şebekeye bağl1 enerji sisteminin maliyeti 11304.57 TL (1366.9 \$) olarak hesaplanmıştır [37]. 
Tasarlanan sistemlerin $\mathrm{kWh}$ başına enerji tüketimleri şebeke bağlantısız sistem için $3.88 \mathrm{TL}$, şebekeye bağlı sistem için 0.514 TL olarak hesaplanmış olup, şebekeye bağlı sistemin incelenen konut için karlı bir enerji yatırımı olduğu görülmektedir. Şebekeden bağımsız enerji sisteminin maliyeti 75749.99 TL (9159.6 \$), şebekeye bağlı enerji sisteminin maliyeti 11304.57 TL (1366.9 \$) olarak hesaplanmış olup, şebeke bağlantısının bakım ve işletme maliyetinin şebekeden bağımsız sisteme kıyasla daha düşük olduğu gözlenmiştir.

Bu çalışmaya benzer olarak Alkan vd. [39] bir evin elektrik ihtiyacını karşılamak için fotovoltaik sistem tasarımı gerçekleştirmiştir. Şebekeye bağlı ve şebekeden bağımsız olmak üzere iki farklı şekilde oluşturulan sistem tasarımlarında şebekeden bağımsız sabit sistem maliyetinin yaklaşık 11000 \$ olarak gerçekleşeceği belirtilmiştir. Türkdoğan vd. [24] 40 hanelik bir topluluğun elektrik ve termal yük ihtiyaçlarının karşılanması amacıyla HOMER programıyla şebekeden bağımsız olarak tasarlanan hibrit sistemin kurulum maliyeti 215958 \$, operasyon maliyeti 18029 \$ ve tüm projenin net bugünkü maliyeti 598958 \$ olarak hesaplanmıştır. Hane başına 15000 \$ değerinde yapılacak enerji yatırımının 25 yıllık elektrik ve 1sıtma ihtiyacını karşılayabileceği öngörülmektedir.

\section{Sonuçlar}

Yenilenebilir enerji kaynaklarından yararlanma çalışmaları tüm dünyada olduğu gibi ülkemizde de yaygınlaşmaktadır. Enerji üretiminde birçok alanda kullanım olanağı bulunan yenilenebilir enerji sistemleri, konutların enerji ihtiyacını karşılama açısından büyük avantajlar barındırmaktadır. Güneş enerjisine dayalı üretim sistemleri;

- Çevre dostu, yerli ve yenilenebilir kaynak niteliğinde olması

- İşletme masrafinın düşük olması

- Kullanıldığı bölgelerde istihdam olanaklarını arttırmas1

- Enerjide dışa bağımlılığı azaltması

- -Enerji üretiminde iletim ve dağıtım kayıplarının önlenmesi gibi birçok önemli avantaj sağlamaktadır.

$\mathrm{Bu}$ çalışmada, çatı uygulamalarında yoğun olarak tercih edilen fotovoltaik güneş panellerinin evsel elektrik üretimi amacıyla Bursa'nın Yıldırım ilçesindeki müstakil bir konut için şebekeye bağlı ve şebekeden bağımsız hibrit enerji üretim sistemi tasarımı yapılmıştır. Sistemlerin $\mathrm{kWh}$ başına enerji tüketimleri şebekeden bağımsız sistem için $3.88 \mathrm{TL}$, şebekeye bağlı sistem için 0.514 TL olarak hesaplanmış; şebekeye bağlı şekilde işletilen sistemin maliyet açısından daha uygun olduğu belirlenmiştir. 2020 yılı elektrik tüketim verileri dikkate alındığında, 1087 TL olan yıllık enerji masrafının şebekeye bağlı olarak işletilen yenilenebilir enerji sistemiyle 489.59 TL'ye düştüğü belirlenmiştir. Sağlanan bu tasarrufla enerji sisteminin fotovoltaik panel ve dönüştürücüden oluşan yenilenebilir kısmının kendini 8.4 y1lda amorti edebileceği bulunmuştur. Elektrik üretiminde yenilenebilir enerji kaynaklarından yararlanma oranının arttırılmasının, fosil yakıtlara olan ihtiyacın düşürülmesi hususunda en etkili çözüm yolu olduğu ve bu yakıtların oluşturduğu çevresel ve ekonomik baskının azaltılmasında önemli bir rol oynayacağı düşünülmektedir.

\section{Çıkar çatışması}

Yazarlar çıkar çatışması olmadığını beyan etmektedir.

Benzerlik oranı (iThenticate): $\% 10$

\section{Kaynaklar}

[1] S. Uçar ve N. Kokulu, Antalya bölgesinde yeni tasarlanacak binalarda güneş panellerinin kullanım potansiyelinin incelenmesi. 4. Ulusal Yapı Kongresi ve Sergisi, sayfa 377-386, Antalya, Türkiye, 6-8 Aralık 2018.

[2] E. Keskin, Türkiye iklim koşullarında fotovoltaik güç sistemlerinin tasarımı ve maliyet analizi. Yüksek Lisans Tezi, Hacettepe Üniversitesi Fen Bilimleri Enstitüsü, Türkiye, 2012.

[3] BP, Statistical review of world energy 2019. https://www.bp.com/content/, Accessed 10 March 2021.

[4] IEA, Key world energy statistics 2019. https://webstore.iea.org/key-world-energy-statistics-20 19, Accessed 10 April 2021.

[5] A.N. Çelik ve F. Koç, Polikristal tür bir fotovoltaik panelin I-V karakteristiğinin analitik modellenmesi ve deneysel doğrulanması. Düzce Üniversitesi Bilim ve Teknoloji Dergisi, 8, 2491-2515, 2020. https://doi.org/10.29130/dubited.789691

[6] EÜAŞ, 2019 Y1lı Elektrik Üretimi ve Ticareti Sektör Raporu. Strateji Geliştirme Dairesi Başkanlığı.

[7] T. C. Enerji ve Tabii Kaynaklar Bakanlığı, Dünya ve Türkiye Enerji ve Tabii Kaynaklar Görünümü Raporu, 1-83, 2017.

[8] R. Kayabaşı ve M. Kaya, Fotovoltaik modüllerin atık 1sılarından termoelektrik jeneratör ile elektrik üretimi. Avrupa Bilim ve Teknoloji Dergisi, 16, 310-324, 2019. https://doi.org/10.31590/ejosat.562859

[9] M. Oral, Solar energy potential of Turkey and evaluation of PV applications in local scale: case of Karabük province. International Journal of Geography and Geography Education (IGGE), 42, 482-503, 2020. https://doi.org/10.32003/igge.743513

[10] E. F. Akyürek, K. Geliş ve M. Yoladı, Farklı gölgeleme durumlarının fotovoltaik panel karakteristiği üzerine etkisi. Gümüşhane Üniversitesi Fen Bilimleri Enstitüsü Dergisi, 11 (1), 161-168, 2021. https://doi.org/10.17 714/gumusfenbil.766232

[11] Anonim, Güneş. https://enerji.gov.tr/bilgi-merkezi-ene rji-gunes, Accessed 4 April 2021.

[12] M. Eremkere, Fotovoltaik tasarımların teknik, ekonomik ve çevresel açılardan analizi: Tekirdağ Bağcılık Araştırma Enstitüsü üzüm suyu işleme tesis çatısı örneği. Yüksek Lisans Tezi, Tekirdağ Namık Kemal Üniversitesi Fen Bilimleri Enstitüsü, Türkiye, 2019.

[13] E. Özgür, Türkiye'de güneş enerjisi. https://www.mmo.org.tr/sites, Accessed 5 April 2021.

[14] TEİAŞ, Kurulu Güç Raporu- Aralık 2020. Yük Tevzi Dairesi Başkanlığı. 
[15] M. Güllü ve Z. Kartal, Türkiye'de yenilenebilir enerji kaynaklarının istihdam etkisi. Sakarya İktisat Dergisi, 10 (1), 36-65, 2021.

[16] G. Bayrak ve M. Cebeci, Balık çiftlikleri için tasarlanan, şebekeden bağımsız, 1.1 kW'lık kurulu güce sahip PV sistemin performans analizi. $6^{\text {th }}$ International Advanced Technologies Symposium, pp. 167-171, Elazığ, Türkiye, 16-18 May 2011.

[17] M. Anbarcı, Ö. Giran ve İ.H. Demir, Uluslararası yeşil bina sertifika sistemleri ile Türkiye'deki bina enerji verimliliği uygulaması. e-Journal of New World Sciences Academy, 7 (1), 368-383, 2012. https://do i.org/10.12739/nwsaes.v7i1.5000066898

[18] M. E. Çamlıbel, G. Alhanlığlu ve D. Uğurlu, Türkiye'de yeni yapılacak konut projelerinin enerji verimliliği ile elde edilecek tasarruf ve bu tasarrufun ulusal enerji ihtiyacını ne seviyede azaltacağının analizi. Journal of Istanbul Technical University Foundation, 65, 62-68, 2014.

[19] U. Yilmaz, Gökçeada'da yenilenebilir enerji kaynaklarıyla elektrik üretimi. Yüksek Lisans Tezi, İstanbul Teknik Üniversitesi Fen Bilimleri Enstitüsü, Türkiye, 2008.

[20] A. Nayir ve R. Pecen, Yenilenebilir enerji sistemleri gözlemleme ve uygulama laboratuarı. ElektrikElektronik ve Bilgisayar Sempozyumu (FEEB 2011), sayfa 279-283, Elazığ, 2011.

[21] M. Altın, (Fotovoltaik malzeme ile) elektrik üreten cepheler ve çatılar. http://www.solar-academy.com/ menuis/Elektrik-Ureten-Cepheler-ve-Catilar 020009.p df , Accessed 28 June 2021.

[22] E. A. Yılmaz ve H. C. Öziç, Türkiye'nin yenilenebilir enerji potansiyeli ve gelecek hedefleri. Ordu Üniversitesi Sosyal Bilimler Araştırmaları Dergisi, 8 (3), 525-535, 2018.

[23] Z. Öztürk, S. Tosun ve A. Öztürk, Örnek bir hibrit yenilebilir enerji sisteminin HOMER ile modellenmesi, ekonomik ve teknik yönden analizleri. Bayburt Üniversitesi Fen Bilimleri Dergisi, 2 (2), 286-299, 2019.

[24] S. Türkdoğan, M.T. Mercan ve T. Çatal, Şebekeden bağımsız hibrit enerji sistemleri kullanılarak 40 hanelik bir topluluğun elektrik ve termal yük ihtiyacının karşılanması: teknik ve ekonomik analizleri. Avrupa Bilim ve Teknoloji Dergisi, (18), 476-485, 2020. https://doi.org/10.31590/ejosat.688048

[25] R. Behçet, H. Oral ve H. Gül, Adıyaman ilinin güneş enerjisi potansiyeli ve kullanımı. Batman Üniversitesi Yaşam Bilimleri Dergisi, 3 (2), 52-67, 2013.

[26] E. Akyüz, M. Bayraktar ve Z. Oktay, Hibrid yenilenebilir enerji sistemlerinin endüstriyel tavukçuluk sektörü için ekonomik açıdan değerlendirilmesi: Bir uygulama. Balıkesir Üniversitesi Fen Bilimleri Enstitüsü Dergisi, 11 (2), 44-54, 2009.
[27] S. Türkdoğan, S. Dilber ve B. Çam, Hibrit enerji sistemlerinin şebekeden bağımsız bir çiftlik evinde uygulanabilirliğinin ekonomik ve teknik açıdan incelenmesi. Sinop Üniversitesi Fen Bilimleri Dergisi, 3 (2), 52-65, 2018. https://doi.org/10.33484/sinopfbd 382391

[28] K. Özbay ve M. Sarışık, Yatlarda kullanılan yenilenebilir enerji kaynaklarından güneş enerjisi üzerine bir değerlendirme. Journal of Gastronomy Hospitality and Travel, 3 (2), 234-243, 2020. https ://doi.org/10.33083/joghat.2020.46

[29] F. Yazıcı, M.E. Başoğlu ve B. Çakır, Akıllı şebeke bileşenleri ve yapısal analizi. EMO Bilimsel Dergi, 8(2), 121-126, 2018.

[30] G. Singh,P. Baredar,A. Singh and D. Kurup, Optimal sizing and location of PV, wind and battery storage for electrification to an Island: A case study of Kavaratti, Lakshadweep. Journal of Energy Storage, 12, 78-86, 2017. https://doi.org/10.1016/j.est.2017.04.003

[31] Anonim, Bursa 2020 nüfusu. https://www.nufusu.com/ il/bursa-nufusu, Accessed 11 March 2021.

[32] T.C. Kültür ve Turizm Bakanlığı, Bursa ili genel bilgiler. Bursa İl Kültür ve Turizm Müdürlügü. https://bursa.ktb.gov.tr/TR-70228/bursa-ili-genel-bilgi ler.html, Accessed 11 March 2021.

[33] R. Erkoç, Güneş enerji santrallerinin modellenmesi, ekonomik analizi ve değerlendirme: Almanya ve Türkiye uygulamaları. Yüksek Lisans Tezi, Ordu Üniversitesi Fen Bilimleri Enstitüsü, Türkiye, 2019.

[34] H. Zahboune, S. Zouggar, G. Krajacic, P.S. Varbanov, M. Elhafyani and E. Ziani, Optimal hybrid renewable energy design in autonomous system using modified electric system cascade analysis and homer software. EnergyConversion and Management, 126, 909-922, 2016. http://dx.doi.org/10.1016/ j.enconman.2016 08. 061

[35] Anonim, Bursa güneş enerjisi potansiyel atlas1. https://gepa.enerji.gov.tr/MyCalculator/pages/16.aspx , Accessed 4 April 2021.

[36] Anonim, Bursa akaryakit fiyatlar1. https://www opet .com.tr/bursa-akaryakit-fiyatlari Accessed 22 April 2021.

[37] Anonim, Dolar ne kadar? https://www.trthaber.com/ha ber/ekonomi/, Accessed 22 April 2021.

[38] Anonim, Devlete elektrik satış fiyatı 2020. https://www.powerenerji.com/devlete-elektrik-satis-fi yati-2020.html. , Accessed 22 April 2021.

[39] S. Alkan, A. Öztürk, S. Zavrak, S. Tosun ve E. Avc1, Bir evin elektrik enerjisi ihtiyacını karşılayacak fotovoltaik sistemin kurulumu. Eleco 2014 Elektrik Elektronik - Bilgisayar ve Biyomedikal Mühendisliği Sempozyumu, sayfa 78-82, Bursa, Türkiye, 27 - 29 Kasım 2014. 